

\title{
The efficacy and safety of pulse vs. continuous therapy for dermatophyte toenail onychomycosis
}

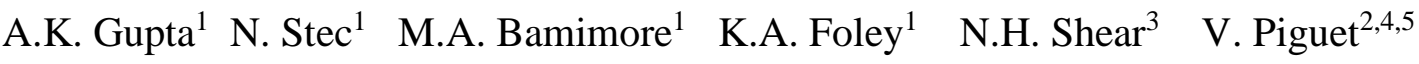 \\ ${ }^{1}$ Mediprobe Research Inc., London, ON, Canada \\ ${ }^{2}$ Division of Dermatology, University of Toronto, ON, Canada \\ ${ }^{3}$ Division of Dermatology, Sunnybrook Health Sciences Centre, Toronto, ON, Canada \\ ${ }^{4}$ Division of Dermatology, Women's College Hospital, Toronto, ON, Canada \\ ${ }^{5}$ Division of Infection and Immunity, Cardiff University School of Medicine, Cardiff, UK \\ Correspondence: A.K. Gupta. E-mail: agupta@execulink.com
}

\section{Abstract}

\section{Background}

Onychomycosis is a chronic, fungal infection of the nails. Complete cure remains challenging, but oral antifungal medications have been successful in managing the fungus for a significant proportion of patients. Treatment with these drugs can be continuous or intermittent, albeit the evidence on their relative efficacies remains unclear.

\section{Objective}

To determine the relative effectiveness and safety of pulse versus continuous administration, of three common oral therapies for dermatophyte onychomycosis, by conducting multipletreatment meta-analysis.

\section{Methods}

This systematic review and network meta-analysis compared the efficacy (as per mycological cure) and adverse event rates of three oral antifungal medications in the treatment of dermatophyte toenail onychomycosis, namely terbinafine, itraconazole and fluconazole. A total of 30 studies were included in the systematic review, while 22 were included in the network meta-analysis.

\section{Results}

The likelihood of mycological cure was not significantly different between continuous and pulse regimens for each of terbinafine and itraconazole. Use of continuous terbinafine for 24 weeks - but not 12 weeks - was significantly more likely to result in mycological cure than continuous itraconazole for 12 weeks or weekly fluconazole for 9-12 months. Rank probabilities demonstrated that 24-week continuous treatment of terbinafine was the most effective. There were no significant differences in the likelihood of adverse events between any continuous and pulse regimens of terbinafine, itraconazole and fluconazole. Drug treatments were similar to placebo in terms of their likelihood of producing adverse events.

\section{Conclusion}

More knowledge about the fungal life cycle and drugs' pharmacokinetics in nail and plasma could further explain the relative efficacy and safety of the pulse and continuous treatment regimens. Our results indicate that in the treatment of dermatophyte toenail onychomycosis, 
the continuous and pulse regimens for terbinafine and itraconazole have similar efficacies and rates of adverse events.

\section{INTRODUCTION}

Onychomycosis is a persistent fungal infection of the nails and adjacent skin, manifesting as discoloration, thickening of the nail and onycholysis. ${ }^{1}$ It is the most common nail pathology accounting for $90 \%$ of toenail infections worldwide. ${ }^{1}$ Most cases of onychomycosis are caused by dermatophytes, namely Trichophyton (T. rubrum and T. mentagrophytes) and Epidermophyton. ${ }^{2}$ Onychomycosis is considered a chronic infection and can be difficult to treat, especially in susceptible populations such as those with diabetes, poor peripheral circulation, HIV and immunosuppression and the elderly. ${ }^{3-7}$ Additional factors that can contribute to disease progression or recurrence include humid environments, occlusive footwear, nail injuries or genetic predisposition..$^{8,9}$

The goal of treatment is to completely eradicate the fungal organism and return the nail to a clear and healthy baseline. Mycological cure and complete cure are two treatment endpoints used to evaluate cure. Mycological cure is defined by negative potassium hydroxide $(\mathrm{KOH})$ preparation and negative fungal culture, whereas complete cure is defined as $100 \%$ clear nail in addition to mycological cure. The options for treating onychomycosis have become broader within the last two decades. Some of the most effective treatments for this condition are oral antifungal medications, namely terbinafine, itraconazole and fluconazole. Typically, these antifungal agents generate high mycological cure rates and are considered safe for most patients. ${ }^{10}$ They can be used continuously for several weeks or intermittently (pulsed) at a higher dose. Previous meta-analyses of pulse and continuous therapies have generated ambiguous results - for example, continuous terbinafine resulted in a higher mycological cure than intermittent terbinafine, yet both result in similar complete cure, for which mycological cure is a prerequisite. ${ }^{11}$ In the case of itraconazole, the pulsed treatment resulted in better mycological and complete cure rates. ${ }^{12}$ There are few head-to-head clinical studies and no meta-analyses comparing regimens of terbinafine to regimens of itraconazole.

Network meta-analysis (NMA) indirectly compares interventions using a common treatment group (e.g. placebo) to combine studies that make different comparisons into the same analysis. ${ }^{13}$ The NMA gathers information indirectly, allowing for estimation of comparative effects that have not been investigated head-to-head in randomized controlled trials (RCTs). ${ }^{14}$ To visualize and interpret the evidence produced by oral antifungal pulse and continuous therapies, a network meta-analysis (NMA) was conducted. ${ }^{15}$ This is the first study using NMA to compare pulse and continuous systemic therapies for toenail onychomycosis.

\section{METHODS}

\section{Systematic review}

The systematic review and meta-analysis was conducted in adherence to the steps outlined in the modified PRISMA 2015 Checklist for network meta-analysis (Table S2). Studies were eligible for inclusion if they met the following criteria: studies were randomized controlled trials (RCTs) of oral antifungal treatments for toenail dermatophyte onychomycosis in adult patients 18 years of age or older and published in the English language. The RCTs could be multiple-arm trials, using placebo or vehicle controls, active comparators (i.e. another antifungal treatment) or both. Onychomycosis was required to be diagnosed mycologically by study investigators using $\mathrm{KOH}$ preparations and fungal cultures. Both tests are used to 
determine whether a fungus is present, the species and viability. Only oral antifungal therapies were eligible for inclusion.

Outcomes of interest included mycological cure, complete cure, adverse events and dropout rates due to adverse events caused by the drug. Mycological cure was defined as negative results from potassium hydroxide $(\mathrm{KOH})$ microscopy and a negative fungal culture. Complete cure was defined as mycological cure in addition to $100 \%$ clear nail. Adverse events (AEs) was defined as the proportion of patients experiencing any adverse event, and dropout rates included patients who stopped participation explicitly due to AEs thought to be caused by the drug. The study endpoints chosen were as close to 48 weeks as possible.

\section{Database search and study selection}

The literature search was conducted using the PubMed database on 27 February 2019 with no date limitation. The search query was '(onychomycosis OR tinea unguium) AND (oral* OR systemic*)'. Reference mining for additional studies or studies missed by the PubMed search was also performed. Author NS screened titles and abstracts, reviewed full texts and extracted data from eligible studies. Author KAF evaluated the included studies and the extracted data. Figure 1 outlines the search and inclusion process.

\section{Data extraction}

Treatment effects were evaluated based on intention-to-treat (ITT) cure rates wherever possible. To ensure consistency among included studies and clinical relevance, some decisions regarding treatment and regimens were made about potential studies - for example, oral ketoconazole and griseofulvin were excluded because they are no longer indicated for onychomycosis due to hepatotoxicity concerns or limited efficacy. ${ }^{16-18}$ Additionally, fluconazole doses of 150, 300 and $450 \mathrm{mg}$ weekly for 9-12 months were collapsed because they were shown to have equal efficacy. ${ }^{19}$ Clinically relevant doses of oral terbinafine ( 250 or $500 \mathrm{mg}$ pulsed) and itraconazole (200 or $400 \mathrm{mg}$ pulsed) were included when used for 3 4 months.

\section{Quality of evidence and risk-of-bias assessment}

The details regarding quality of evidence and risk-of-bias assessment for this review can be found in Appendix S1 (Supplementary methods).

\section{Statistical analyses}

Analyses were performed separately for treatment efficacy and adverse events. Prior to our multiple-treatment comparisons, we performed meta-analyses of randomized controlled trial studies for pairwise treatment comparisons using RevMan 5.3 software (The Nordic Cochrane Centre, The Cochrane Collaboration, Copenhagen, Denmark). Our network metaanalyses were performed in RStudio software (version 1.1.463, Rstudio, Inc., Boston, MA, USA), whereby the gemtc and 'pcnetmeta' packages were used. ${ }^{20,21}$

Network plot of treatments were created for adverse events and efficacy; in such plots, a node represents a treatment, while an edge (i.e. the line between two nodes) corresponds to a direct comparison between the two treatments, from at least two studies. We performed an armbased network meta-analysis under a Bayesian random-effects model that assumed binomial likelihood with a probit link function; in the 'pcnetmeta' package, Markov chain Monte Carlo (MCMC) sampling is done in R through JAGS. ${ }^{20}$ We used three MCMC chains with 200000 
iterations per chain, and we used an inverse-Wishart prior for variance/covariance of random effects. We computed relative risks (RRs) and their corresponding 95\% credible intervals (CIs) to compare treatments with each other for their efficacy and adverse events. Rank probabilities were produced and were used to estimate each treatment's surface under the cumulative ranking (SUCRA) curve using the equation:

SUCRA $_{k}=\frac{\sum_{c=1}^{b-1} \operatorname{Cum}_{k, c}}{b-1}$

where $k=$ treatment and $b=$ total number of treatments; $c=1$ corresponds to the probability of the first rank (i.e. the probability of the given treatment being the most effective option). ${ }^{22}$

For instance, if a network is constituted of four treatments, each one is given four rank probabilities. The first, second, third and fourth rank probabilities correspond to the likelihood that the given treatment is the first, second, third and fourth (i.e. least) most effective option. The numerator portion of the right-hand side of the equation (i.e. $\sum_{c=1}^{b-1} \operatorname{Cum}_{k, c}$ three corresponds to sum of the treatment's cumulative probabilities for the first rank is excluded. The value of the right-hand side of the equation is always within the range of zero to one inclusive.

For mycological cure, higher occurrence translated to better treatment, while lower occurrence corresponded to better treatment for adverse events.

\section{RESULTS}

\section{Search results}

The PubMed search yielded a total of 1042 items. The total number of items meeting the inclusion criteria was 28 , which included 13 items selected from reference mining of other publications. Detailed information for the studies meeting inclusion criteria is presented in Table 1 . The quantitative analysis included 22 studies from 20 publications that met the criteria required for performing network meta-analysis (reported cure rates and adverse events). At least two RCTs for a specific treatment were required for inclusion into the NMA, and each trial must have contributed at least two treatment arms to the network. In total, there were 4205 randomized patients included in the NMA.

The treatments eligible for the network included the following: terbinafine $250 \mathrm{mg}$ daily for 12 weeks (Terb250_12w), 16 weeks (Terb_16w) and 24 weeks (Terb250_24w); terbinafine $500 \mathrm{mg}$ daily for 1 week per month, pulsed 3 times (Terb500_p*3); itraconazole $400 \mathrm{mg}$ daily for 1 week per month, pulsed 3 times (ITR400*3) or 4 times (ITR400*4); itraconazole $200 \mathrm{mg}$ daily for 12 weeks (ITR200_12w); and fluconazole 150, 300 or $450 \mathrm{mg}$ once weekly for 9-12 months (Flu_9-12). Ravuconazole, posaconazole and combination therapies could not be included in the network.

We were able to perform NMA for mycological cure and adverse events, but there was a lack of studies reporting complete cure for oral antifungals. This is likely because many of the studies were conducted prior to the use of consistent outcome measures. 


\section{Risk of bias}

The included trials were judged as 'low risk', 'unclear risk' or 'high risk' of bias (Figure S1). One study was rated as low risk of bias for all domains while two studies were rated as low risk of bias for all but one domain. ${ }^{23-25}$ Most studies were rated as 'unclear risk' for most domains as trial procedures were rarely outlined in detail. Appropriate procedures for randomization sequence generation (32\%) and for allocation concealment (14\%) were infrequently reported. ${ }^{23-29}$ Low risk of bias was found for blinding of participants/personnel and outcome assessors in $41 \%^{23,24,26,29-32}$ and $18 \% \%^{23,25,33,34}$ of studies, respectively.

\section{Quality of evidence}

Evidence for direct comparisons of mycological cure was of moderate or high quality (Table S3.1), with the exceptions of Terb250_12w vs. ITR400*3 and Terb250_16w vs. ITR $400 * 4$ which were of low quality. For adverse event, four of six comparisons were of low or very low quality (Table S3.2), with Terb250_12w vs. ITR200_12w and Flu_9-12 vs. placebo the exceptions with moderate quality of evidence.

\section{Efficacy and safety of oral monotherapy vs. placebo}

Comparing monotherapies to placebo resulted in significantly greater risk ratios (RRs) of achieving mycological cure with all treatments. The most successful treatments compared to placebo were continuous Terb250_24w with RR $=11.00$ (CI 6.08, 19.30) and continuous Terb250_16w, RR = 8.90 (CI 4.16, 16.40). The risk of experiencing adverse events in patients receiving any treatment was not significantly different from that of placebo (Table $\underline{2}$, Figure S2).

\section{Comparisons of monotherapies}

Continuous regimens of terbinafine were not significantly different in efficacy compared to pulse regimens of terbinafine; likewise, continuous and pulse regimens of itraconazole were not significantly different. Continuous Terb250_24w was significantly more likely to achieve mycological cure than continuous ITR200_12w (RR = 1.63, CI 1.14, 2.26). All other continuous and pulse regimens of terbinafine and itraconazole showed similar likelihood in achieving mycological cure and were not significantly different from each other (Tables 2 and 3).

A continuous treatment of Terb250_24w was significantly more likely to achieve mycological cure than weekly Flu_9-12 (RR = 1.72, CI 1.06, 3.44). Weekly fluconazole was not significantly different from any itraconazole regimens, pulse terbinafine and continuous 12- and 16-week terbinafine (Tables 2 and 3).

There were not enough studies reporting adverse events for continuous Terb250_24w and Terb500_p*3 to be included in the network. However, for all other treatments, the relative risk of experiencing adverse events with any other treatment was equivalent (Table 2, Figure S3). That is, there was no significant difference in likelihood of experiencing adverse events among continuous or pulse regimens of terbinafine, itraconazole and fluconazole. 


\section{Inconsistency analysis}

Inconsistency analysis performed using the gemtc $\mathrm{R}$ package is presented in Table 4 . The results showed that there was no significant inconsistency between the direct and indirect evidence from the network.

\section{Ranking of treatments by efficacy}

Using SUCRA analysis, continuous Terb250_24w was ranked the most likely to result in mycological cure (95.97\%), followed by continuous Terb250_16w (70.71\%) and continuous Terb250_12w (67.42\%) (Table 5).

\section{Ranking of treatments by safety}

Data were coded so that a higher SUCRA probability corresponds to a lower number of adverse events. Terbinafine and itraconazole regimens were similar in their probabilities of leading to adverse events (Table 6).

\section{DISCUSSION}

This review and network meta-analysis was completed in order to compare the effectiveness of pulsed and continuous oral antifungal therapies for the treatment of dermatophyte toenail onychomycosis. We were able to evaluate mycological cure rates and adverse events for the included studies. All oral antifungal regimens were significantly more likely to produce mycological cure than placebo. Continuous terbinafine $250 \mathrm{mg}$ for 24 weeks was significantly more likely to produce mycological cure than continuous itraconazole $200 \mathrm{mg}$ for 12 weeks and weekly fluconazole (150-450 mg). This was reflected in the SUCRA rankings, where the treatment with the highest probability of mycological cure was continuous terbinafine $250 \mathrm{mg}$ for 24 weeks $(95.97 \%)$. Quality of evidence for mycological cure was mostly moderate or high, providing confidence in the results.

The FDA-approved dose of continuous terbinafine $250 \mathrm{mg}$ for 12 weeks was not significantly different from other continuous terbinafine regimens (16 and 24 weeks), pulse terbinafine $500 \mathrm{mg}$, weekly fluconazole, or itraconazole regimens (continuous itraconazole $200 \mathrm{mg}, 3$ and 4-pulse itraconazole $400 \mathrm{mg}$ ) in the ability to produce mycological cure. There were also no significant differences between continuous and pulse regimens of itraconazole in mycological cure.

Our meta-analysis results differ from other findings. A meta-analysis of terbinafine regimens found that continuous treatment was more likely to result in mycological cure than pulsed treatments. The same analysis revealed them to have similar efficacy for complete cure. ${ }^{11}$ In contrast, our results suggest that terbinafine treatments are all similar in terms of efficacy. Inclusion criteria were similar as well, though a retrospective study was used in the other meta-analysis.

In terms of safety, the terbinafine pulse and continuous regimens were not significantly different; similarly, the itraconazole pulse and continuous therapies were not significantly different. In addition, terbinafine, itraconazole and fluconazole did not significantly differ in their safety and did not significantly differ from placebo. We did not have sufficient data to include continuous terbinafine for 24 weeks (Terb250_24w) or pulse terbinafine (Terb500_p*3) in the adverse events analysis. Quality of evidence for adverse events was low 
or very low for most comparisons, and thus, we cannot have confidence in the SUCRA rankings.

Surface under the cumulative ranking rankings are able to summarize the efficacy of treatments, but may be misleading outside of the context of the relative effects of the NMA. ${ }^{35}$ A treatment's surface under the cumulative ranking curve (SUCRA) can be described as a numerical rank, where the rank could be in relation to adverse events associated with the treatment or the treatment's efficacy. Easily misinterpreted, the literature cautions against taking SUCRA rankings at surface value - especially when making clinical decisions ${ }^{.35,36}$ SUCRA rankings are arguably meaningless on their own for several reasons; namely, the estimation of SUCRA does not take into account the certainty level of the evidence, and thus may be computed from evidence with low certainty. Evidence with high imprecision (i.e. a high degree of uncertainty) arguably leads to high imprecision of a treatment's rank, which in turn explains how the difference in rank between two treatments could be due to chance; in other words, the highest-ranked and lowest-ranked treatments may not be significantly different from each other in terms of efficacy or occurrence of adverse events (thus, their difference in rank is due to chance alone). Therefore, our SUCRA values - as per adverse events - of approximately $92 \%$ and $33 \%$ for ITR $400 * 4$ and placebo, respectively, and the statistically non-significant difference between the two, in terms of occurrence in adverse events (risk ratio $=0.475,95 \% \mathrm{CI}=0.122,1.060$ ), is not incongruent.

Based on the model proposed by Baker et al. and considering the fungal life cycle, pulse therapy should theoretically be as effective as, or more effective than, continuous therapies. ${ }^{37}$ With pulse therapy, the sudden high concentration of an antifungal drug eliminates hyphae, preventing the formation of new spores but perhaps sparing already-present spores. During the 'off' portion of pulse therapy, these spores may sense a more favourable host environment and germinate into hyphae if the drug concentration falls low enough. Thus, hyphae would be present that the next pulse could eliminate. With continuous therapies, a high concentration of drug in the nail is maintained for a long period of time, eradicating hyphae and preventing the germination of existing spores (and possibly eliminating them as well). There is no 'off' period for the spores to become more susceptible hyphae, so it can be assumed that high, stable drug concentrations in the nail must be maintained for spores to be eliminated. In practice, neither continuous nor pulse therapy is necessarily better - in both cases, patients should be clipping their nails, which manually decreases the fungal load from the nail. We can speculate that in the case of antifungal pulse therapy, it is possible that the drug concentration in the nail is maintained during the 'off' period at a level that is not favourable to induce hypha formation. In both continuous and repeated pulse therapies, it may be that residual spores that have not been eliminated by the end of therapy are left to germinate, possibly contributing to the recalcitrant nature of onychomycosis.

The results generated by our NMA suggest that continuous terbinafine ( 24 weeks' duration) treatment is most likely to result in mycological cure, a treatment that is twice the length of approved treatment. Studies support terbinafine courses lasting < 24 weeks being equally effective in the treatment of onychomycosis, and the drugs are detectable in nail clippings as soon as 3 weeks into treatment. ${ }^{38-40}$ Thus, our results complement these findings as we found no significant differences between continuous terbinafine regimens. Additionally, terbinafine has been cited as a superior drug in terms of its fungicidal action, which may be explained by its ability to suppress conidium production in T. rubrum $^{41,42}$ In theory, pulse therapy presents itself as a more advantageous strategy for reasons discussed. Ultimately, the published evidence demonstrates that there are no differences in efficacy or safety between pulse and continuous regimens of terbinafine and no differences between pulse and continuous regimens of itraconazole. More research about pulse therapy efficacy and safety is required for a more robust comparison, as currently there are limited data 
Conflicts of interest

AKG is a clinical trials investigator for Moberg Pharma and Bausch Health Canada and a speaker for Bausch Health Canada. NS, MAB and KAF are employees of Mediprobe Research Inc., which conducts clinical trials under the supervision of AKG. VP undertakes advisory work for Pfizer, AbbVie, Janssen, UCB, Novartis, Almirall and Celgene. VP has received departmental support from AbbVie, Bausch Health, Celgene, Janssen, LEO Pharma, Lilly, NAOS, Novartis, Pfizer, Pierre-Fabre and Sanofi. NHS has been a consultant to Bausch Health, Celgene, Amgen, AbbVie, Janssen, Sanofi-Genzyme, Leo Pharma, Novartis and UCB.

Funding sources

The authors received no specific funding for this work. 


\section{REFERENCES}

1. Vlahovic TC. Onychomycosis. Clin Podiatr Med Surg 2016; 33: 305- 318.

2. Welsh O, Vera-Cabrera L, Welsh E. Onychomycosis. Clin Dermatol 2010; 28: 151159.

3. Elewski BE. Onychomycosis: pathogenesis, diagnosis, and management. Clin Microbiol Rev 1998; 11: 415- 429.

4. Faergemann J, Correia O, Nowicki R, Ro B-I. Genetic predisposition-understanding underlying mechanisms of onychomycosis. J Eur Acad Dermatol Venereol 2005; 19( Suppl 1): 17- 19.

5. Gupta AK, Gupta MA, Summerbell RC et al. The epidemiology of onychomycosis: possible role of smoking and peripheral arterial disease. J Eur Acad Dermatol Venereol 2000; 14: 466- 469.

6. Gupta AK, Taborda P, Taborda V et al. Epidemiology and prevalence of onychomycosis in HIV-positive individuals. Int J Dermatol 2000; 39: 746- 753.

7. Gupta AK, Konnikov N, MacDonald $P$ et al. Prevalence and epidemiology of toenail onychomycosis in diabetic subjects: a multicentre survey. Br J Dermatol 1998; 139: 665-671.

8. Gupta AK, Versteeg SG, Shear NH, Piguet V, Tosti A, Piraccini BM. A practical guide to curing onychomycosis: how to maximize cure at the patient, organism, treatment, and environmental level. Am J Clin Dermatol 2019; 20: 123-133.

9. Adams C, Athanasoula E, Lee W, Mahmudova N, Vlahovic TC. Environmental and genetic factors on the development of onychomycosis. J Fungi Basel Switz 2015; 1: 211- 216.

10. Darkes MJM, Scott $\amalg$, Goa KL. Terbinafine: a review of its use in onychomycosis in adults. Am J Clin Dermatol 2003; 4: 39-65.

11. Gupta AK, Paquet M, Simpson F, Tavakkol A. Terbinafine in the treatment of dermatophyte toenail onychomycosis: a meta-analysis of efficacy for continuous and intermittent regimens. J Eur Acad Dermatol Venereol 2013; 27: 267- 272.

12. Havu $\mathrm{V}$, Brandt $\mathrm{H}$, Heikkilä $\mathrm{H}$ et al. A double-blind, randomized study comparing itraconazole pulse therapy with continuous dosing for the treatment of toe-nail onychomycosis. Br J Dermatol 1997; 136: 230- 234.

13. Petticrew $M$, Rehfuess $E$, Noyes J et al. Synthesizing evidence on complex interventions: how meta-analytical, qualitative, and mixed-method approaches can contribute. J Clin Epidemiol 2013; 66: 1230- 1243.

14. Caldwell DM, Ades AE, Higgins JPT. Simultaneous comparison of multiple treatments: combining direct and indirect evidence. BMJ 2005; 331: 897-900.

15. Lu G, Ades AE. Combination of direct and indirect evidence in mixed treatment comparisons. Stat Med 2004; 23: 3105- 3124.

16. Health Canada. Health Canada Endorsed Important Safety Information on Ketoconazole [Internet]. Ketoconazole - Risk of Potentially Fatal Liver Toxicity - For Health Professionals. 2013 [cited 2014 Sep 17] [WWW document].

17. European Medicines Agency. European Medicines Agency recommends suspension of marketing authorisations for oral ketoconazole [Internet]. 2013 [WWW document]. URL

18. U.S. Food and Drug Administration. FDA Drug Safety Communication: FDA limits usage of Nizoral (ketoconazole) oral tablets due to potentially fatal liver injury and risk of drug interactions and adrenal gland problems. 2013 
19. Gupta AK, Drummond-Main C, Paquet M. Evidence-based optimal fluconazole dosing regimen for onychomycosis treatment. J Dermatol Treat 2013; 24: 75- 80.

20. Lin L, Zhang J, Hodges JS, Chu H. Performing arm-based network meta-analysis in $\mathrm{R}$ with the pcnetmeta Package. J Stat Softw 2017; 80: 1- 25.

21. RStudio: Integrated Development for R [Internet]. Boston, MA: RStudio, Inc.; 2016

22. Salanti G, Ades AE, loannidis JPA. Graphical methods and numerical summaries for presenting results from multiple-treatment meta-analysis: an overview and tutorial. $J$ Clin Epidemiol 2011; 64: 163-171.

23. Warshaw EM, Fett DD, Bloomfield HE et al. Pulse versus continuous terbinafine for onychomycosis: a randomized, double-blind, controlled trial. J Am Acad Dermatol 2005; 53: 578- 584.

24. De Backer M, De Keyser P, De Vroey C, Lesaffre E. A 12-week treatment for dermatophyte toe onychomycosis: terbinafine $250 \mathrm{mg} /$ day vs. itraconazole 200 mg/day-a double-blind comparative trial. Br J Dermatol 1996; 134( Suppl 46): 16 17: discussion 38.

25. Gupta AK, Gover MD, Lynde CW. Pulse itraconazole vs. continuous terbinafine for the treatment of dermatophyte toenail onychomycosis in patients with diabetes mellitus. J Eur Acad Dermatol Venereol 2006; 20: 1188- 1193.

26. Bräutigam M, Nolting S, Schopf RE, Weidinger G. Randomised double blind comparison of terbinafine and itraconazole for treatment of toenail tinea infection. Seventh Lamisil German Onychomycosis Study Group. BMJ 1995; 311: 919-922.

27. Elewski B, Pollak R, Ashton S, Rich P, Schlessinger J, Tavakkol A. A randomized, placebo- and active-controlled, parallel-group, multicentre, investigator-blinded study of four treatment regimens of posaconazole in adults with toenail onychomycosis. Br J Dermatol 2012; 166: 389- 398.

28. Goodfield MJ, Andrew L, Evans EG. Short term treatment of dermatophyte onychomycosis with terbinafine. BMJ 1992; 304: 1151.

29. ]Singal A, Pandhi D, Das S, Yadav P. Comparative efficacy of continuous and pulse dose terbinafine regimes in toenail dermatophytosis: a randomized double-blind trial. Indian J Dermatol Venereol Leprol 2015; 81: 363.

30. van der Schroeff JG, Cirkel PK, Crijns MB et al. A randomized treatment durationfinding study of terbinafine in onychomycosis. Br J Dermatol 1992; 126( Suppl 39): 36- 39.

31. Sigurgeirsson B, Billstein S, Rantanen T, et al. L.I.ON Study: efficacy and tolerability of continuous terbinafine (Lamisil) compared to intermittent itraconazole in the treatment of toenail onychomycosis. Lamisil vs. Itraconazole in Onychomycosis. $\mathrm{Br} \mathrm{J}$ Dermatol 1999; 141( Suppl 56): 5- 14.

32. Elewski BE, Scher RK, Aly R et al. Double-blind, randomized comparison of itraconazole capsules vs. placebo in the treatment of toenail onychomycosis. Cutis 1997; 59: 217- 220.

33. Gupta AK, Lynch LE, Kogan N, Cooper EA. The use of an intermittent terbinafine regimen for the treatment of dermatophyte toenail onychomycosis. J Eur Acad Dermatol Venereol 2009; 23: 256- 262.

34. Gupta AK, Konnikov N, Lynde CW. Single-blind, randomized, prospective study on terbinafine and itraconazole for treatment of dermatophyte toenail onychomycosis in the elderly. J Am Acad Dermatol 2001; 44: 479- 484.

35. Mbuagbaw L, Rochwerg B, Jaeschke $R$ et al. Approaches to interpreting and choosing the best treatments in network meta-analyses. Syst Rev 2017; 12;6(1): 79.

36. Bafeta A, Trinquart L, Seror R, Ravaud P. Reporting of results from network metaanalyses: methodological systematic review. BMJ 2014; 11: g1741. 
37. Baker CM, Ferrari MJ, Shea K. Beyond dose: pulsed antibiotic treatment schedules can maintain individual benefit while reducing resistance. Sci Rep 2018; 8: 1- 7.

38. Clayton YM. In vitro activity of terbinafine. Clin Exp Dermatol 1989; 14: 101- 103.

39. Shadomy S, Espinel-Ingroff A, Gebhart RJ. In-vitro studies with SF 86-327, a new orally active allylamine derivative. Sabouraudia 1985; 23: 125- 132.

40. Finlay AY. Pharmacokinetics of terbinafine in the nail. Br J Dermatol 1992; 126( Suppl 39): $28-32$.

41. Yin Z, Xu J, Luo D. A meta-analysis comparing long-term recurrences of toenail onychomycosis after successful treatment with terbinafine versus itraconazole. $J$ Dermatol Treat 2012; 23: 449-452.

42. Yazdanparast SA, Barton RC. Arthroconidia production in Trichophyton rubrum and a new ex vivo model of onychomycosis. J Med Microbiol 2006; 55: 1577- 1581. 


\section{Figure 1}

Flow chart of search strategy and literature inclusion.

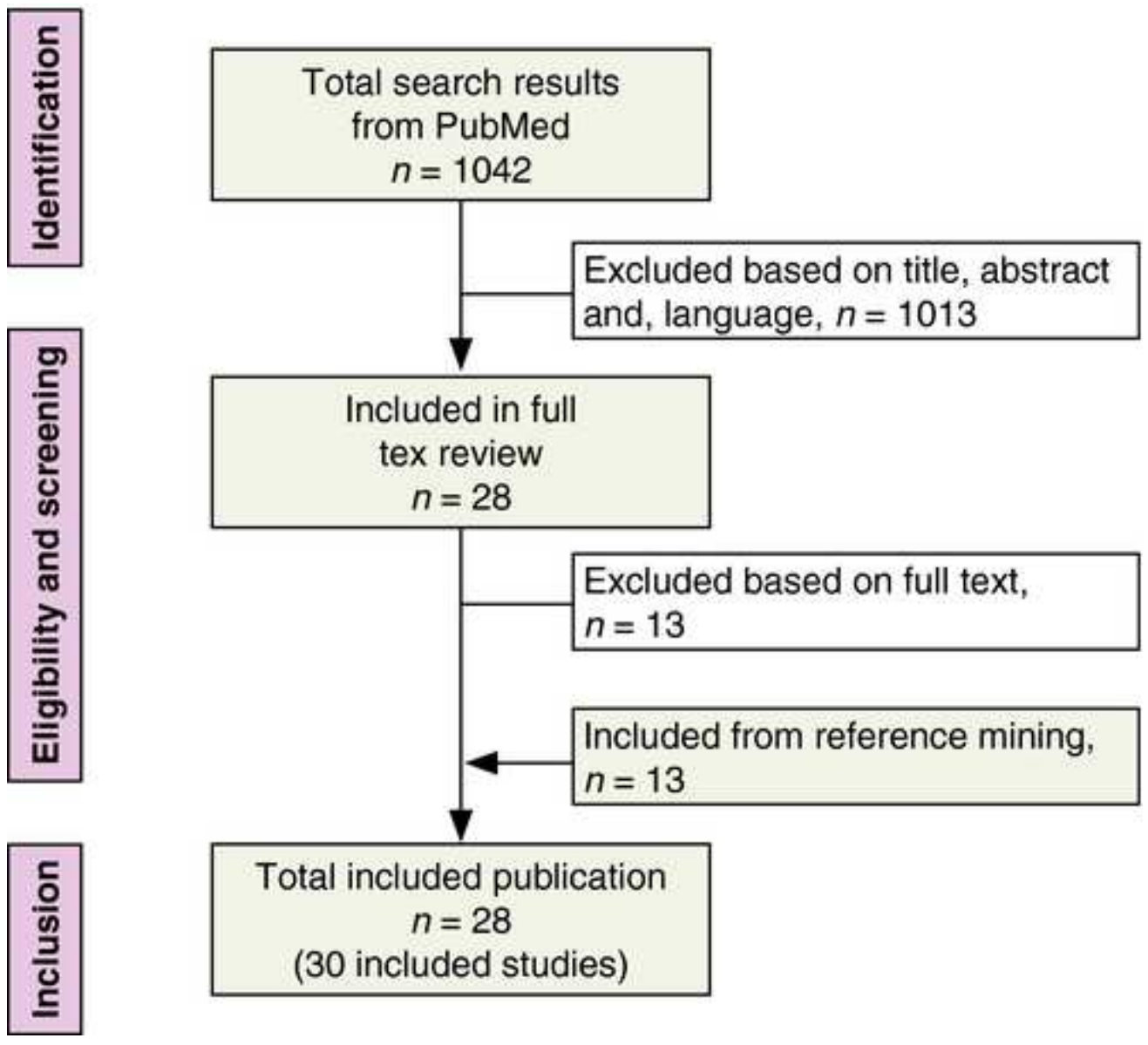




\section{Table 1. List of included studies}

\begin{tabular}{|c|c|c|c|c|c|c|c|c|}
\hline Author & Patients ( $n$, age) & Treatment & Dosing & MC & $\mathrm{CC}$ & $\begin{array}{l}\text { Assessment } \\
\text { week }\end{array}$ & Adverse events & $\begin{array}{c}\text { Dropout rate (due to } \\
\text { AE/drug) }\end{array}$ \\
\hline \multicolumn{9}{|l|}{ Included in NMA } \\
\hline \multirow{4}{*}{$\begin{array}{l}\text { Billstein et al. } \\
\text { (1999) }\end{array}$} & & T1. TERB $250 \mathrm{mg}$ & T1. daily for 12 weeks & T1. 11/15 (73\%) & \multirow{4}{*}{-} & \multirow{4}{*}{48} & \multirow{4}{*}{-} & \multirow{4}{*}{-} \\
\hline & $n=63$ & T2. TERB $250 \mathrm{mg}$ & T2. daily for 16 weeks & $\mathrm{T} 2.10 / 14(71 \%)$ & & & & \\
\hline & mean age $=42.3-46.9$ & T3. TERB $250 \mathrm{mg}$ & T3. daily for 24 weeks & T3. 17/18 (94\%) & & & & \\
\hline & & P. placebo & P. daily for 24 weeks & P. $0 / 16$ & & & & \\
\hline \multirow{3}{*}{$\begin{array}{l}\text { Bräutigam et al. } \\
\text { (1996) }\end{array}$} & $n=170$ & T1. TERB $250 \mathrm{mg}$ & \multirow{3}{*}{ Daily for 12 weeks } & T1. 70/86 (81\%) & \multirow{3}{*}{-} & \multirow{3}{*}{52} & T1. 38/95 (40\%) & $\mathrm{T} 1: 3 / 95(3.15 \%)$ \\
\hline & & & & & & & & \\
\hline & mean age $=49$ & T2. ITR $200 \mathrm{mg}$ & & T2. 53/84 (63\%) & & & T2. 47/98 (48\%) & T2: 4/98 (4.1\%) \\
\hline \multirow{2}{*}{$\begin{array}{l}\text { De Backer et al. } \\
\text { (1996) }\end{array}$} & \multirow{2}{*}{$n=372$} & T1. TERB $250 \mathrm{mg}$ & & $\begin{array}{l}\mathrm{T} 1.119 / 186 \\
(70.8 \%)\end{array}$ & $\begin{array}{l}\text { T1: 62/186 } \\
(33 \%)\end{array}$ & \multirow{2}{*}{48} & T1. 71/186 (38.6\%) & \multirow{2}{*}{-} \\
\hline & & T2. ITR $200 \mathrm{mg}$ & Daily for 12 weeks & $\begin{array}{l}\mathrm{T} 2.77 / 186 \\
(45.8 \%)\end{array}$ & $\begin{array}{l}\text { T2: } 40 / 186 \\
(22 \%)\end{array}$ & & T2. 65/186 (35.4\%) & \\
\hline \multirow{2}{*}{$\begin{array}{l}\text { Degreef et al. } \\
\text { (1999) }\end{array}$} & $n=292$ & T1. ITR $200 \mathrm{mg}$ & \multirow{2}{*}{ Daily for 12 weeks } & $\begin{array}{l}\mathrm{T} 1.78 / 146 \\
(53 \%)\end{array}$ & \multirow[t]{2}{*}{-} & \multirow{2}{*}{48} & T1. 32/146 (22\%) & T1. 2/146 (1.4\%) \\
\hline & ages $18-65$ & T2. TERB $250 \mathrm{mg}$ & & $\begin{array}{l}\mathrm{T} 2.79 / 146 \\
(54 \%)\end{array}$ & & & T2. 34/146 (23\%) & T2. $11 / 146(7.5 \%)$ \\
\hline \multirow{4}{*}{$\begin{array}{l}\text { Drake et al. } \\
\text { (1997) }\end{array}$} & \multirow{4}{*}{$\begin{array}{l}n=358 \\
\text { ages } 18-70\end{array}$} & T1. TERB $250 \mathrm{mg}$ & $\begin{array}{l}\text { T1. daily for } 12 \text { weeks }+ \text { placebo } \\
12 \text { weeks }\end{array}$ & $\begin{array}{l}\text { T1. 99/142 } \\
(70 \%)\end{array}$ & & & & \multirow{4}{*}{$\begin{array}{l}\text { T1. 2/142 (1.4\%) } \\
\text { T2. 3/145 (2.1\%) }\end{array}$} \\
\hline & & T2. TERB $250 \mathrm{mg}$ & T2. daily for 24 weeks & T2. $126 / 145$ & - & 48 & $9 / 358(2.5 \%)$ & \\
\hline & & & 12. dainy lot 24 weeks & $(87 \%)$ & & & & \\
\hline & & P. placebo & P. daily for 24 weeks & P. $6 / 71(9 \%)$ & & & & \\
\hline
\end{tabular}




\begin{tabular}{|c|c|c|c|c|c|c|c|c|}
\hline Author & Patients $(n$, age $)$ & Treatment & Dosing & \multicolumn{2}{|c|}{ Results } & $\begin{array}{l}\text { Assessment } \\
\text { week }\end{array}$ & Adverse events & $\begin{array}{c}\text { Dropout rate (due to } \\
\text { AE/drug) }\end{array}$ \\
\hline \multirow{8}{*}{$\begin{array}{l}\text { Elewski et al. } \\
\text { (2012) }\end{array}$} & \multirow{8}{*}{$n=218$} & & & $\begin{array}{l}\text { MC } \\
\text { T1. 13/37 } \\
(37.1 \%)\end{array}$ & $\begin{array}{r}\mathbf{C C} \\
\text { T1. 8/37 } \\
(22.2 \%)\end{array}$ & \multirow{8}{*}{48} & & \\
\hline & & T1. POS $100 \mathrm{mg}$ & T1. daily for 24 weeks & T2. 26/37 & T2. 20/37 & & T1. 30/37 (83\%) & T1. 1/37 (2.7\%) \\
\hline & & T2. POS $200 \mathrm{mg}$ & T2. daily for 24 weeks & $(70.3 \%)$ & $(54.1 \%)$ & & T2. 29/37 (78\%) & $\mathrm{T} 2.2 / 37(5.4 \%)$ \\
\hline & & T3. POS $400 \mathrm{mg}$ & T3. daily for 24 weeks & $\begin{array}{l}\text { T3. } 28 / 36 \\
(78.8 \%)\end{array}$ & $\begin{array}{l}\text { T3. } 15 / 36 \\
(41.7 \%)\end{array}$ & & T3. 26/36 (72\%) & T3. 4/36 (11\%) \\
\hline & & T4. POS $400 \mathrm{mg}$ & T4. daily for 12 weeks & T4. $15 / 36$ & T4. $8 / 36$ & & T4. 27/36 (75\%) & T4. 4/36 (11\%) \\
\hline & & T5. TERB $250 \mathrm{mg}$ & T5. daily for 12 weeks & $(42.9 \%)$ & $(22.2 \%)$ & & T5. 24/36 (67\%) & T5. 0/36 \\
\hline & & P. placebo & P. daily for 24 weeks & $\begin{array}{l}\text { T5. 25/36 } \\
(71.4 \%)\end{array}$ & $\begin{array}{l}\text { T5. } 13 / 36 \\
(36.1 \%)\end{array}$ & & P. $25 / 36(71 \%)$ & P. $1 / 36(2.7 \%)$ \\
\hline & & & & P. $1 / 36(3.1 \%)$ & P. $0 / 36$ & & & \\
\hline \multirow{7}{*}{$\begin{array}{l}\text { Elewski et al. } \\
\text { (1997) }\end{array}$} & $n=68$ & T1. ITR $200 \mathrm{mg}$ & \multirow{7}{*}{ Daily for 12 weeks } & T1. 24/35 (69\%) & & \multirow{7}{*}{48} & $\mathrm{~T} 1: 19 / 36(53 \%)$ & \multirow{7}{*}{-} \\
\hline & ages $18-70$ & P. placebo & & P. $2 / 33(6 \%)$ & & & P: 21/37 (57\%) & \\
\hline & $n=82$ & T1. ITR $200 \mathrm{mg}$ & & T1. $18 / 38(47 \%)$ & & & $\mathrm{T} 1: 24 / 39(62 \%)$ & \\
\hline & & & & & - & & & \\
\hline & ages $23-69$ & P. placebo & & P. $3 / 35(9 \%)$ & & & P: $16 / 35(46 \%)$ & \\
\hline & $n=73$ & T1. ITR $200 \mathrm{mg}$ & & T1. 17/37 (46\%) & & & $\mathrm{T} 1: 28 / 37(76 \%)$ & \\
\hline & ages $22-69$ & P. placebo & & P. $1 / 36(3 \%)$ & & & P: $23 / 37$ (62\%) & \\
\hline \multirow{3}{*}{$\begin{array}{l}\text { Goodfield } \\
\text { (1992) }\end{array}$} & \multirow{3}{*}{$n=75$} & T1. TERB $250 \mathrm{mg}$ & \multirow{3}{*}{ Daily for 12 weeks } & T1. 37/45 (82\%) & \multirow{3}{*}{ - } & \multirow{3}{*}{36} & T1. 25/45 (33\%) & \multirow{3}{*}{-} \\
\hline & & & & & & & & \\
\hline & & P. placebo & & P. $3 / 25(12 \%)$ & & & P. $14 / 25(41 \%)$ & \\
\hline \multirow{2}{*}{$\begin{array}{l}\text { Gupta et al. } \\
\text { (2006) }\end{array}$} & \multirow{2}{*}{$n=70$} & T1. ITR $400 \mathrm{mg}$ & T1. daily for 1 week $/$ month $\times 3$ & $\begin{array}{l}\text { T1.30/35 } \\
(85.7 \%)\end{array}$ & \multirow{2}{*}{-} & \multirow{2}{*}{48} & & \multirow{2}{*}{ T1. 1/35 (2.9\%) } \\
\hline & & T2. TERB $250 \mathrm{mg}$ & T2. daily for 12 weeks & $\begin{array}{l}\text { T2. } 23 / 35 \\
(65.7 \%)\end{array}$ & & & - & \\
\hline
\end{tabular}




\begin{tabular}{|c|c|c|c|c|c|c|c|c|}
\hline Author & Patients $(n$, age $)$ & Treatment & Dosing & MC & $\mathrm{CC}$ & $\begin{array}{l}\text { Assessment } \\
\text { week }\end{array}$ & Adverse events & $\begin{array}{c}\text { Dropout rate (due to } \\
\text { AE/drug) }\end{array}$ \\
\hline \multirow[b]{2}{*}{$\begin{array}{l}\text { Gupta et al. } \\
\text { (2001) B }\end{array}$} & $n=101$ & T1. TERB $250 \mathrm{mg}$ & T1. daily for 12 weeks & $\mathrm{T} 1.32 / 50(64 \%)$ & & \multirow[b]{2}{*}{72} & T1. 5/50 (10\%) & \multirow[b]{2}{*}{$0 / 101$} \\
\hline & age $\geq 60$ & T2. ITR $400 \mathrm{mg}$ & T2. daily for 1 week/month $\times 3$ & $\begin{array}{l}\mathrm{T} 2.32 / 51 \\
(62.7 \%)\end{array}$ & & & $\mathrm{T} 2.7 / 51(13.7 \%)$ & \\
\hline \multirow{3}{*}{$\begin{array}{l}\text { Gupta et al. } \\
\text { (2009) }\end{array}$} & & T1. TERB $250 \mathrm{mg}$ & T1. 4 weeks on, 4 off, 4 on & $\begin{array}{l}\mathrm{T} 1.33 / 63 \\
(52.4 \%)\end{array}$ & & \multirow{3}{*}{36} & T1. $14 / 63(22.2 \%)$ & \\
\hline & $n=142$ & T2. TERB $250 \mathrm{mg}$ & T2. daily for 12 weeks & T2. $22 / 40(55 \%)$ & & & $\mathrm{T} 2.7 / 40(17.5 \%)$ & T3. 2/39 (5.1\%) \\
\hline & & T3. ITR $400 \mathrm{mg}$ & T3. daily for 1 week/month $\times 3$ & $\begin{array}{l}\text { T3. } 22 / 39 \\
(56.4 \%) \\
\end{array}$ & & & T3. $4 / 39(10.3 \%)$ & \\
\hline \multirow{2}{*}{$\begin{array}{l}\text { Havu et al. } \\
\text { (1997) }\end{array}$} & $n=129$ & T1. ITR $200 \mathrm{mg}$ & T1. daily for 12 weeks & $\begin{array}{l}\mathrm{T} 1.42 / 65 \\
(64.6 \%)\end{array}$ & \multirow{2}{*}{-} & \multirow{2}{*}{48} & T1. $11 / 65(17 \%)$ & T1. 3/65 (4.6\%) \\
\hline & median age $=41-45$ & T2. ITR $400 \mathrm{mg}$ & T2. daily for 1 week/month $\times 3$ & $\begin{array}{l}\mathrm{T} 2.42 / 64 \\
(65.6 \%)\end{array}$ & & & $\mathrm{T} 2.9 / 64(14 \%)$ & $\mathrm{T} 2.3 / 64(4.7 \%)$ \\
\hline \multirow{4}{*}{$\begin{array}{l}\text { Ling et al. } \\
\text { (1998) }\end{array}$} & \multirow{4}{*}{$n=384$} & T1. FLU $450 \mathrm{mg}$ & $\begin{array}{l}\text { T1. weekly for } 4 \text { month + placebo } \\
\text { for } 5 \text { month }\end{array}$ & T1. 28/96 (29\%) & \multirow{4}{*}{-} & \multirow{4}{*}{36} & T1. 74/96 (77.1\%) & T1. 6/96 (6.25\%) \\
\hline & & & $\begin{array}{l}\text { T2. weekly for } 6 \text { month + placebo } \\
\text { for } 3 \text { month }\end{array}$ & $\mathrm{T} 2.32 / 94(34 \%)$ & & & T2. 76/94 (80.8\%) & T2. $1 / 94(1 \%)$ \\
\hline & & T3. FLU $450 \mathrm{mg}$ & T3. weekly for 9 month & T3. 50/98 (51\%) & & & T3. 71/98 (72.4\%) & T3. 3/98 (3.1\%) \\
\hline & & P. placebo & P. weekly for 9 month & T4. 6/96 (6.25\%) & & & P. $70 / 96(73 \%)$ & P. 7/96 (8.3\%) \\
\hline \multirow{4}{*}{$\begin{array}{l}\text { Scher et al. } \\
\text { (1998) }\end{array}$} & & T1. FLU $150 \mathrm{mg}$ & & $\begin{array}{l}\mathrm{T} 1.37 / 89 \\
(41.6 \%)\end{array}$ & & \multirow{4}{*}{52} & T1. 74/89 (83\%) & T1. 4/89 (4.5\%) \\
\hline & $n=439$ & T2. FLU $300 \mathrm{mg}$ & FLU. once weekly for 12 months & T2. 44/88 (50\%) & & & T2. $74 / 88(84 \%)$ & T2. $9 / 88(10.2 \%)$ \\
\hline & ages $18-70$ & T3. FLU $450 \mathrm{mg}$ & P. once weekly for 12 months & $\begin{array}{l}\text { T3. } 49 / 92 \\
(53.2 \%)\end{array}$ & & & T3. $79 / 92(86 \%)$ & T3. 5/92 (5.4\%) \\
\hline & & P. placebo & & P. $11 / 92(12 \%)$ & & & P. $72 / 92(78 \%)$ & P. $6 / 92(6.5 \%)$ \\
\hline
\end{tabular}




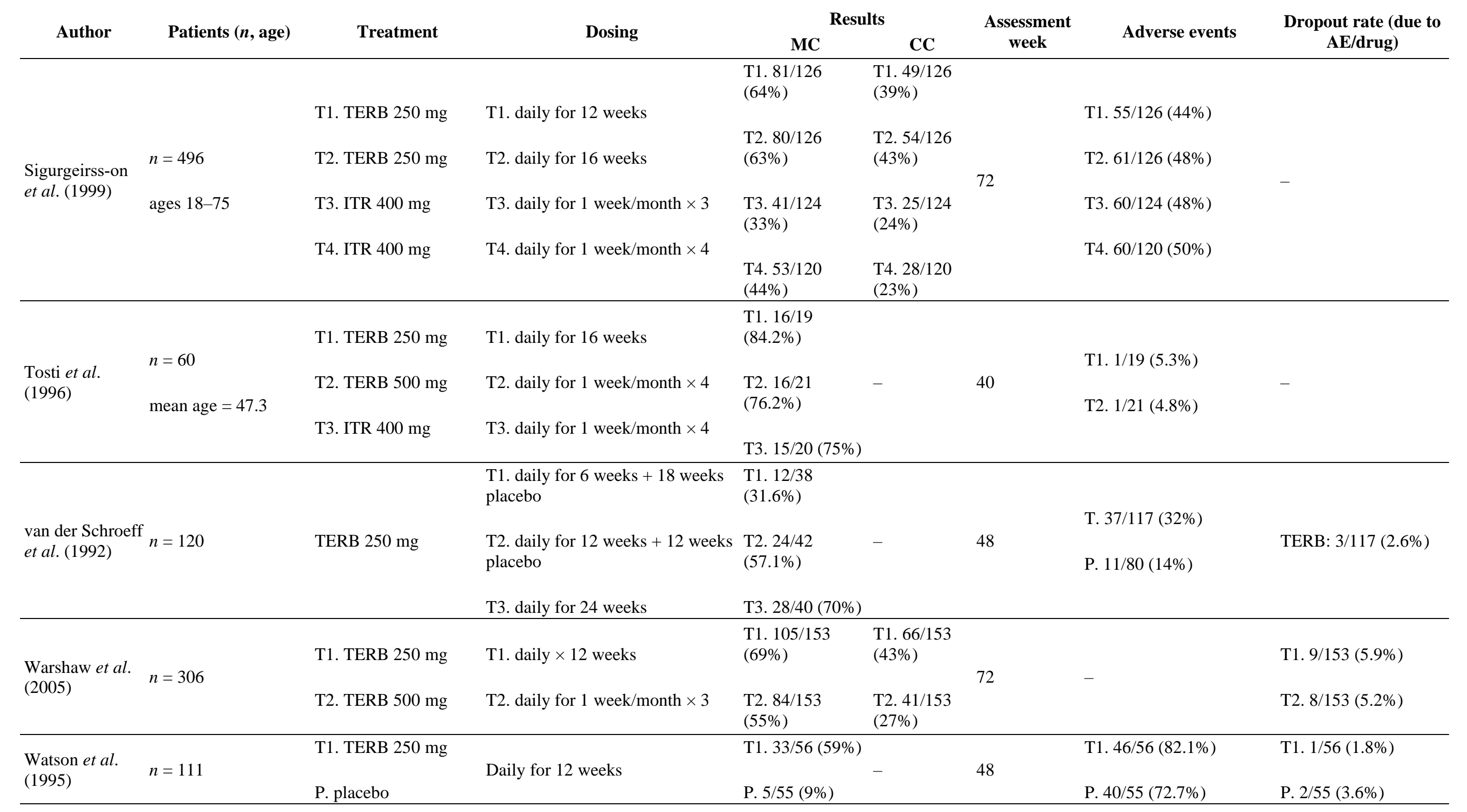




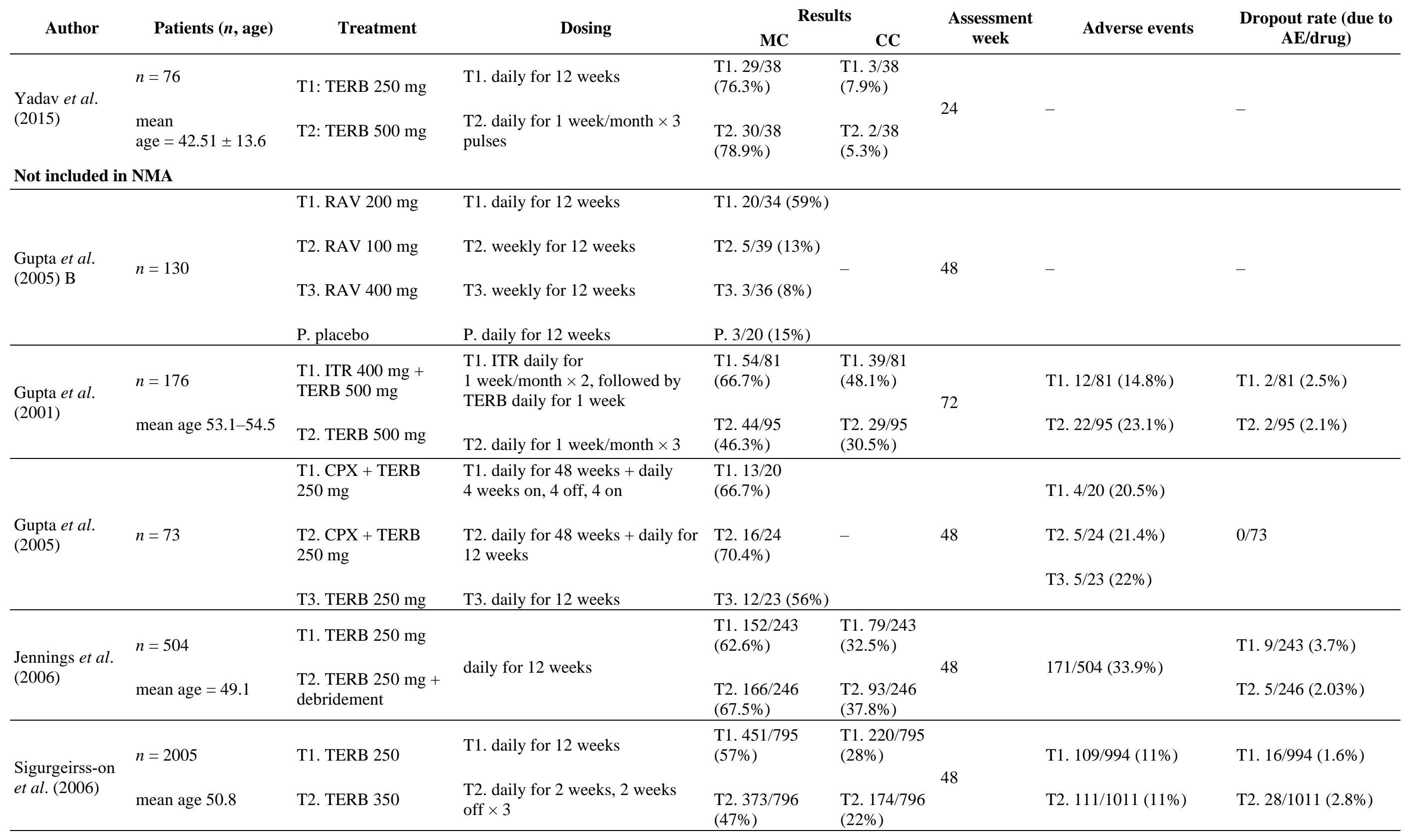




\begin{tabular}{|c|c|c|c|c|c|c|c|c|}
\hline Author & Patients (n, age) & Treatment & Dosing & \multicolumn{2}{|c|}{ Results } & $\begin{array}{l}\text { Assessment } \\
\text { week }\end{array}$ & Adverse events & $\begin{array}{c}\text { Dropout rate (due to } \\
\text { AE/drug) }\end{array}$ \\
\hline \multirow{6}{*}{$\begin{array}{l}\text { Sigurgeirss-on } \\
\text { et al. (2013) }\end{array}$} & \multirow{6}{*}{$n=584$} & T1. ALBA $100 \mathrm{mg}$ & T1. 1x weekly, 36 weeks & $\begin{array}{l}\mathrm{T} 1.40 / 117 \\
(34 \%)\end{array}$ & $\begin{array}{l}\text { T1. 14/117 } \\
(12 \%)\end{array}$ & \multirow{6}{*}{52} & \multirow{6}{*}{$414 / 584(71 \%)$} & \multirow{2}{*}{ T1. 11/117 (9.4\%) } \\
\hline & & T2. ALBA $200 \mathrm{mg}$ & T2. 1x weekly, 36 weeks & $\begin{array}{l}\text { T2. 50/117 } \\
(43 \%)\end{array}$ & $\begin{array}{l}\text { T2. } 24 / 117 \\
(21 \%)\end{array}$ & & & \\
\hline & & T3. ALBA $400 \mathrm{mg}$ & T3. 1x weekly, 36 weeks & T3. $82 / 116$ & T3. 38/116 & & & T3. 7/116 (6.0\%) \\
\hline & & T4. ALBA $400 \mathrm{mg}$ & $\begin{array}{l}\text { T4. } 1 \mathrm{x} \text { weekly, } 24 \text { weeks + } \\
\text { placebo } 12 \text { weeks }\end{array}$ & & $(33 \%)$ & & & T4. 16/117 (13.7\%) \\
\hline & & P. placebo & \multirow{2}{*}{ P. 1x weekly, 36 weeks } & $\begin{array}{l}\text { T4. 63/117 } \\
(54 \%)\end{array}$ & $\begin{array}{l}\text { T4. 30/117 } \\
(26 \%)\end{array}$ & & & \multirow[t]{2}{*}{ P. $8 / 115(6.9 \%)$} \\
\hline & & & & P. $7 / 115(6 \%)$ & P. $0 / 115$ & & & \\
\hline \multirow{2}{*}{$\begin{array}{l}\text { Succi et al. } \\
\text { (2013) }\end{array}$} & $n=41$ & T1: TERB $250 \mathrm{mg}$ & $\begin{array}{l}\text { T1: daily for } 1 \text { week/month + nail } \\
\text { abrasion, for } 6 \text { month }\end{array}$ & T1. $4 / 18(22.2 \%)$ & $\begin{array}{l}\text { T1. } 7 / 18 \\
(38.9 \%)\end{array}$ & \multirow{2}{*}{48} & \multirow{2}{*}{ T1. 1/18 (5.5\%) } & \multirow{2}{*}{-} \\
\hline & mean age $50-56$ & T2: TERB $500 \mathrm{mg}$ & $\begin{array}{l}\text { T2: daily for } 1 \text { week every } \\
2 \text { months + nail abrasion, for } \\
6 \text { month }\end{array}$ & T2. $7 / 18(38.9 \%)$ & $\begin{array}{l}\mathrm{T} 2.8 / 18 \\
(44.4 \%)\end{array}$ & & & \\
\hline \multirow{2}{*}{$\begin{array}{l}\text { Watanabe } \text { et al. } \\
\text { (2018) }\end{array}$} & $n=153$ & T1: F-RVCZ $100 \mathrm{mg}$ & \multirow{2}{*}{ daily for 12 weeks } & $\begin{array}{l}\text { T1. 82/101 } \\
(82 \%)\end{array}$ & $\begin{array}{l}\mathrm{T} 1.60 / 101 \\
(59.4 \%)\end{array}$ & \multirow[t]{2}{*}{48} & T1. 84/101 (83.2\%) & \multirow[t]{2}{*}{-} \\
\hline & mean age $=58.4$ & P. placebo & & P. $10 / 52(20 \%)$ & $\begin{array}{l}\text { P. } 3 / 52 \\
(5.8 \%)\end{array}$ & & P. 42/52 (80.8\%) & \\
\hline
\end{tabular}

- $\mathrm{MC}$ is mycological cure, and CC is complete cure. 
Table 2.

Relative risks and corresponding $95 \%$ credible intervals. Each cell gives the effect of the column-defining intervention relative to the row-defining intervention. RRs above the labels are mycological cure, and RRs below the labels are adverse events. Dashes indicate that AE data were not available for continuous terbinafine for 24 weeks or pulse terbinafine

\begin{tabular}{|c|c|c|c|c|c|c|c|c|}
\hline ITR200_12w & $\begin{array}{l}0.904(0.600, \\
1.490)\end{array}$ & $\begin{array}{l}0.937(0.572 \\
2.050)\end{array}$ & $\begin{array}{l}1.060(0.645 \\
2.140)\end{array}$ & $\begin{array}{l}0.793(0.578 \\
1.020)\end{array}$ & $\begin{array}{l}0.751(0.507 \\
1.410)\end{array}$ & $\begin{array}{l}6.760(3.750 \\
12.100)\end{array}$ & $\begin{array}{l}0.613(0.442 \\
0.876)\end{array}$ & $\begin{array}{l}0.824(0.544 \\
1.490)\end{array}$ \\
\hline $\begin{array}{l}0.632(0.215 \\
1.420)\end{array}$ & ITR400*3 & $\begin{array}{l}1.040(0.583 \\
2.310)\end{array}$ & $\begin{array}{l}1.170(0.640 \\
2.420)\end{array}$ & $\begin{array}{l}0.880(0.551, \\
1.190)\end{array}$ & $\begin{array}{l}0.832(0.500 \\
1.610)\end{array}$ & $\begin{array}{l}7.450(3.830 \\
13.700)\end{array}$ & $\begin{array}{l}0.681(0.421 \\
1.000)\end{array}$ & $\begin{array}{l}0.914(0.530 \\
1.700)\end{array}$ \\
\hline $\begin{array}{l}0.622(0.157 \\
1.490)\end{array}$ & $\begin{array}{l}0.972(0.263, \\
3.100)\end{array}$ & ITR400*4 & $\begin{array}{l}1.130(0.485 \\
2.410)\end{array}$ & $\begin{array}{l}0.849(0.394, \\
1.260)\end{array}$ & $\begin{array}{l}0.809(0.382, \\
1.540)\end{array}$ & $\begin{array}{l}7.140(2.930, \\
14.100)\end{array}$ & $\begin{array}{l}0.658(0.304, \\
1.040)\end{array}$ & $\begin{array}{l}0.886(0.399 \\
1.670)\end{array}$ \\
\hline $\begin{array}{l}1.510(0.793 \\
2.420)\end{array}$ & $\begin{array}{l}2.380(0.943, \\
6.960)\end{array}$ & $\begin{array}{l}2.390(0.935 \\
9.630)\end{array}$ & Flu_9-12 & $\begin{array}{l}0.748(0.378, \\
1.150)\end{array}$ & $\begin{array}{l}0.715(0.351, \\
1.430)\end{array}$ & $\begin{array}{l}6.350(2.790, \\
12.600)\end{array}$ & $\begin{array}{l}0.582(0.291 \\
0.946)\end{array}$ & $\begin{array}{l}0.785(0.371, \\
1.560)\end{array}$ \\
\hline $\begin{array}{l}0.892(0.549 \\
1.430)\end{array}$ & $\begin{array}{l}1.390(0.680 \\
4.070)\end{array}$ & $\begin{array}{l}1.430(0.611, \\
5.630)\end{array}$ & $\begin{array}{l}0.591(0.366 \\
1.110)\end{array}$ & Terb250_12w & $\begin{array}{l}0.943(0.717 \\
1.730)\end{array}$ & $\begin{array}{l}8.570(5.040 \\
14.700)\end{array}$ & $\begin{array}{l}0.766(0.650 \\
1.060)\end{array}$ & $\begin{array}{l}1.040(0.759 \\
1.830)\end{array}$ \\
\hline $\begin{array}{l}0.625(0.158 \\
1.510)\end{array}$ & $\begin{array}{l}0.984(0.242, \\
3.220)\end{array}$ & $\begin{array}{l}1.000(0.288 \\
3.560)\end{array}$ & $\begin{array}{l}0.418(0.108 \\
1.060)\end{array}$ & $\begin{array}{l}0.730(0.178 \\
1.640)\end{array}$ & Terb250_16w & $\begin{array}{l}8.900(4.160, \\
16.400)\end{array}$ & $\begin{array}{l}0.820(0.444 \\
1.180)\end{array}$ & $\begin{array}{l}1.100(0.572, \\
2.010)\end{array}$ \\
\hline $\begin{array}{l}1.310(0.876 \\
2.080)\end{array}$ & $\begin{array}{l}2.100(0.947 \\
5.890)\end{array}$ & $\begin{array}{l}2.110(0.945 \\
8.220)\end{array}$ & $\begin{array}{l}0.871(0.606 \\
1.540)\end{array}$ & $\begin{array}{l}1.470(1.000 \\
2.290)\end{array}$ & $\begin{array}{l}2.100(0.961, \\
7.950)\end{array}$ & Placebo & $\begin{array}{l}0.091(0.052 \\
0.164)\end{array}$ & $\begin{array}{l}0.123(0.066 \\
0.259)\end{array}$ \\
\hline- & - & - & - & - & - & - & Terb250_24w & $\begin{array}{l}1.340(0.904 \\
2.380)\end{array}$ \\
\hline- & - & - & - & - & - & - & - & Terb500_p*3 \\
\hline
\end{tabular}

- The bold texts in the table correspond to the following abbreviations: Terbinafine $250 \mathrm{mg}$ daily for 12 weeks (Terb250_12w), 16 weeks (Terb_16w), and 24 weeks (Terb250_24w); Terbinafine $500 \mathrm{mg}$ daily for one week per month, pulsed 3 times (Terb500_p*3); Itraconazole 400 mg daily for one week per month, pulsed 3 times (ITR400*3) or 4 times (ITR400*4); Itraconazole $200 \mathrm{mg}$ daily for 12 weeks (ITR200_12w); and Fluconazole $150 \mathrm{mg}$, $300 \mathrm{mg}$, or $450 \mathrm{mg}$ once weekly for 9 to 12 months (Flu_9-12). 
Table 3.

Summary of NMA comparisons of the included systemic treatments for mycological cure (efficacy). Treatments in the same column are not significantly different from each other.

Treatments in different columns are significantly different from each other

$\begin{array}{lll}\text { Treatment } & \text { Treatment } & \begin{array}{c}\text { Control } \\ \text { Placebo }\end{array} \\ \text { Terb250_24w } & \text { Flu_9-12 } & \\ \text { Terb250_16w } & \text { ITR200_12w } & \\ \text { Terb250_12w } & \text { Terb250_16w } & \\ \text { ITR400*3 } & \text { Terb250_12w } & \\ \text { ITR400*4 } & \text { ITR400*3 } & \\ \text { Terb500*3 } & \text { ITR400*4 } & \\ & \text { Terb500*3 }\end{array}$


Table 4.

Results from node-splitting analysis of inconsistency

\begin{tabular}{lll} 
& \multicolumn{1}{c}{ Mycological cure } \\
Treatment 1 & Treatment 2 & $\boldsymbol{P}$-value for inconsistency \\
ITR200_12w & Placebo & 0.8536 \\
ITR200_12w & Terb250_12w & 0.8547 \\
Placebo & Terb250_12w & 0.8479
\end{tabular}

Adverse events

Treatment 1

ITR200_12w

Treatment 2

$P$-value for inconsistency

ITR200_12w

Placebo

0.7612

Placebo

Terb250_12w

0.7522

Terb250_12w

0.7906 
Table 5.

Surface under the cumulative ranking (SUCRA) curve for mycological cure

$\begin{array}{ll}\text { Treatment } & \text { SUCRA } \\ \text { Terb250_24w } & 95.97 \\ \text { Terb250_16w } & 70.71 \\ \text { Terb250_12w } & 67.42 \\ \text { Terb500_p*3 } & 58.78 \\ \text { ITR400*3 } & 47.20 \\ \text { ITR400*4 } & 43.98 \\ \text { ITR200_12w } & 33.87 \\ \text { Flu_9-12 } & 32.25 \\ \text { Placebo } & 0.005\end{array}$


Table 6.

Surface under the cumulative ranking (SUCRA) curve for adverse events. A higher probability corresponds to a lower number of adverse events

$\begin{array}{lc}\text { Treatment } \dagger & \text { SUCRA } \\ \text { ITR400*4 } & 92.49 \\ \text { ITR400*3 } & 92.42 \\ \text { Terb250_16w } & 92.37 \\ \text { Terb250_12w } & 71.84 \\ \text { ITR200_12w } & 60.16 \\ \text { Placebo } & 32.86 \\ \text { Flu_9-12 } & 24.61\end{array}$

- $\quad \dagger$ No adverse events available for Terb250_24w and Terb500_p*3. 
The treatments eligible for the network included the following: terbinafine $250 \mathrm{mg}$ daily for 12 weeks (Terb250_12w), 16 weeks (Terb_16w) and 24 weeks (Terb250_24w); terbinafine $500 \mathrm{mg}$ daily for 1 week per month, pulsed 3 times (Terb500_p*3); itraconazole $400 \mathrm{mg}$ daily for 1 week per month, pulsed 3 times (ITR400*3) or 4 times (ITR400*4); itraconazole $200 \mathrm{mg}$ daily for 12 weeks (ITR200_12w); and fluconazole 150,300 or $450 \mathrm{mg}$ once weekly for 9-12 months (Flu_9-12). Ravuconazole, posaconazole and combination therapies could not be included in the network.

We were able to perform NMA for mycological cure and adverse events, but there was a lack of studies reporting complete cure for oral antifungals. This is likely because many of the studies were conducted prior to the use of consistent outcome measures. 